\title{
UNIVERSITYOF
}

FORWARD

THINKING

WESTMINSTER用

WestminsterResearch

http://www.westminster.ac.uk/westminsterresearch

\section{Doherty Amplifier Linearization in Experiments by Digital Injection Methods}

Atanasković, A., Males-Ilic, N., Djorić, A. and Budimir, D.

This is a copy of the author's accepted version of a paper subsequently published in the proceedings of the 2021 15th International Conference on Telecommunications in Modern Satellite, Cable and Broadcasting Service (TELSIKS 2021). Niš, Serbia 20 - 22 Oct 2021 IEEE . https://doi.org/10.1109/TELSIKS52058.2021.9606416.

The final published version will be available online at:

https://doi.org/10.1109/TELSIKS52058.2021.9606416

(C) 2021 IEEE . Personal use of this material is permitted. Permission from IEEE must be obtained for all other uses, in any current or future media, including reprinting/republishing this material for advertising or promotional purposes, creating new collective works, for resale or redistribution to servers or lists, or reuse of any copyrighted component of this work in other works.

The WestminsterResearch online digital archive at the University of Westminster aims to make the research output of the University available to a wider audience. Copyright and Moral Rights remain with the authors and/or copyright owners. 


\title{
Doherty Amplifier Linearization in Experiments by Digital Injection Methods
}

\author{
Aleksandar Atanasković ${ }^{1}$, Nataša Maleš-Ilić ${ }^{1}$, Aleksandra Đorić ${ }^{1}$, Đurađ Budimir ${ }^{2}$
}

\begin{abstract}
In this paper, the experimental verification of two linearization methods applied on a broadband two-way microstrip Doherty amplifier is performed. The laboratory setups are formed to generate the baseband nonlinear linearization signals of the second-order. After being tuned in magnitude and phase in the digital domain the linearization signals modulate the second harmonics of fundamental carrier. In the first method, adequately processed signals are then inserted at the input and output of the main Doherty amplifier transistor, whereas in the second method, they are injected at the outputs of the Doherty main and auxiliary amplifier transistors. The experimental results are obtained for 16QAM and 64QAM digitally modulated signals.
\end{abstract}

Keywords-Doherty amplifier, baseband signal, second harmonic, linearization, experimental verification.

\section{INTRODUCTION}

The power amplifier characterized by high efficiency is Doherty topology (DA), which is widely used in the contemporary wireless communication systems, especially is required in 5G technology applications. Linear performances of the DA have been achieved by using different linearization methods available in literature such as digital predistortion technique, which is commercially and the most frequently utilized in the recent time [1].

We deployed in earlier work the digital linearization technique [2]-[6] which processes the $\mathrm{I}$ and $\mathrm{Q}$ signals to generate the adequate $2^{\text {nd }}$ order baseband linearization signals adjusted in the magnitudes and phase angles. These signals are then driven at the gate and drain of the amplifier transistor, after modulate the $2^{\text {nd }}$ harmonic of the fundamental carrier, in order to lower the nonlinearity of the single stage PA [2], [5], and the two-way DA [3]-[5]. In [6], DA was linearized by inserting the modulated signals for linearization at the outputs of the main and auxiliary amplifier transistors. The comparison of two digital linearization methods was carried out in simulation on the designed broadband microstrip DA,

\footnotetext{
${ }^{1}$ Aleksandar Atanaskovic, Nataša Maleš Ilić and Aleksandra Đorić are with the Faculty of Electronic Engineering, University of Nis, Aleksandra Medvedeva 14, 18000 Nis, Serbia (e-mails: aleksandar.atanaskovic; natasa.males.ilic)@elfak.ni.ac.rs, alexdjoric@yahoo.com)).

${ }^{2}$ Đurad Budimir is with the University of Westminster, 115 New Cavendish

Street, London, UK, (e-mail: d.budimir@wmin.ac.uk)
}

for different two-tone signal power and maximum tone separation of $30 \mathrm{MHz}$ as well as for OFDM signal.

In this paper, the various experiments are performed on Doherty amplifier fabricated in microstrip technology [4] for evaluation of two linearization methods. The tests were realized for 16QAM signal with useful spectrum bandwidth $1 \mathrm{MHz}$ and 64QAM with spectrum bandwidth of $2 \mathrm{MHz}$. Measured results show the adjacent channel power ration ACPR at dominant third-order intermodulation products and fifth-order intermodulation products.

\section{DA DESIGN}

The measurement set-up shown in Figure 1 was established to verify in experiments the linearization methods developed by our researcher group. The linearization methods of power amplifiers are based on the 2nd-order baseband nonlinear digital signals, which adequately modified and processed in the baseband, modulate the fundamental carrier second harmonic. In order to demonstrate the results of linearization practically NI USRP platforms 292x were used and programmed by LabView software. Useful 16QAM and 64QAM signals, the signals for linearization and their control in magnitude and phase were performed by the USRP platforms. The linearization effects were examined on the fabricated two-way asymmetrical Doherty amplifier operating at $900 \mathrm{MHz}$ central frequency, shown in Figure 2. Detailed description of the Doherty amplifier design can be found in [4]. The maximal transducer gain $9 \mathrm{~dB}$ was measured for the fabricated two-way asymmetrical Doherty amplifier for the carrier amplifier biased in class- $\mathrm{AB}(\mathrm{VD}=5 \mathrm{~V}, \mathrm{VG}=-3 \mathrm{~V})$, and the peaking amplifier operates in class- $\mathrm{C}$ regime $(\mathrm{VD}=$ $5 \mathrm{~V}, \mathrm{VG}=-5 \mathrm{~V}$ ) when AP602A-2 GaAs MESFET transistor was used in amplifying cells. Moreover, measured 1-dB compression point of DA is at $15 \mathrm{dBm}$ output power and $18 \mathrm{dBm}$ maximum output power is achieved. DC bias levels are regulated by the regulator that is shown in Figure 1.

The measurements of output spectra, the adjacent channel power ratios-ACPRs, for the states before and after the linearization carried out for different QAM modulation format and signal power levels were spotted in EXA Signal analyzer N9010A. 


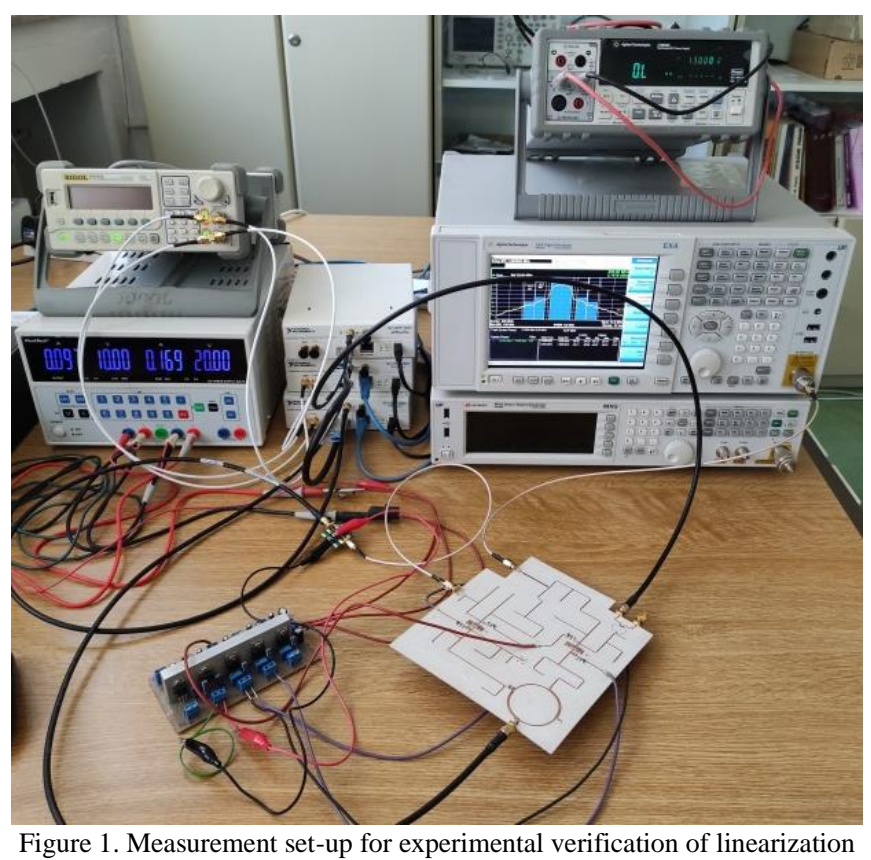
methods 1 and 2

\section{RESULTS OF LINEARIZATION}

Doherty amplifier was tested for 16QAM signal with $1 \mathrm{MHz}$ useful channel bandwidth and also for 64QAM signal with $2 \mathrm{MHz}$ channel bandwidth. Central frequency of operation is $900 \mathrm{MHz}$. The linearization effects were measured on the fabricated DA for different input signal power levels $1 \mathrm{dBm}$ to $5 \mathrm{dBm}$. The presented results shown in Figure 3 to 8 compare the ACPRs obtained without and with applying two digital linearization methods: 1) the firststandard method that injects signals for the linearization at the gate and drain of the transistor in the main cell of the DA and 2) the second-modified method, where the linearization signals are put at the drain of the main and auxiliary amplifier transistors in the DA.

The results of ACPRs are illustrated in the lower and upper adjacent channels (at $\pm 1 \mathrm{MHz}$ and $\pm 2 \mathrm{MHz}$ offset from carrier for 16QAM and 64QAM, respectively) and also in the alternate channels (at $\pm 1.5 \mathrm{MHz}$ and $\pm 3 \mathrm{MHz}$ offset from carrier for 16QAM and 64QAM, respectively). We can observe for $1 \mathrm{dBm}$ input power, that the $\mathrm{ACPR}$ in the adjacent channels is improved by around $6 \mathrm{~dB}$ when method 1 is used and negligibly better by $7 \mathrm{~dB}$ by applying the method 2 , whereas the ACPRs in the alternate channels are slightly deteriorated, but more in method 1. With the increase of input power to $3 \mathrm{dBm}$, the ACPRs observed in the adjacent channels are improved around $3 \mathrm{~dB}$ in the $1^{\text {st }}$ method and $6 \mathrm{~dB}$ in the $2^{\text {nd }}$ method, whereas in alternated channels become negligible better $\left(1 \mathrm{~dB}\right.$ in the $1^{\text {st }}$ method and $2 \mathrm{~dB}$ in the $\left.2^{\text {nd }}\right)$. In case of $5 \mathrm{dBm}$ input power, ACPRs are improved by the almost equal level, i.e. $3 \mathrm{~dB}$ and $4 \mathrm{~dB}$ by linearization

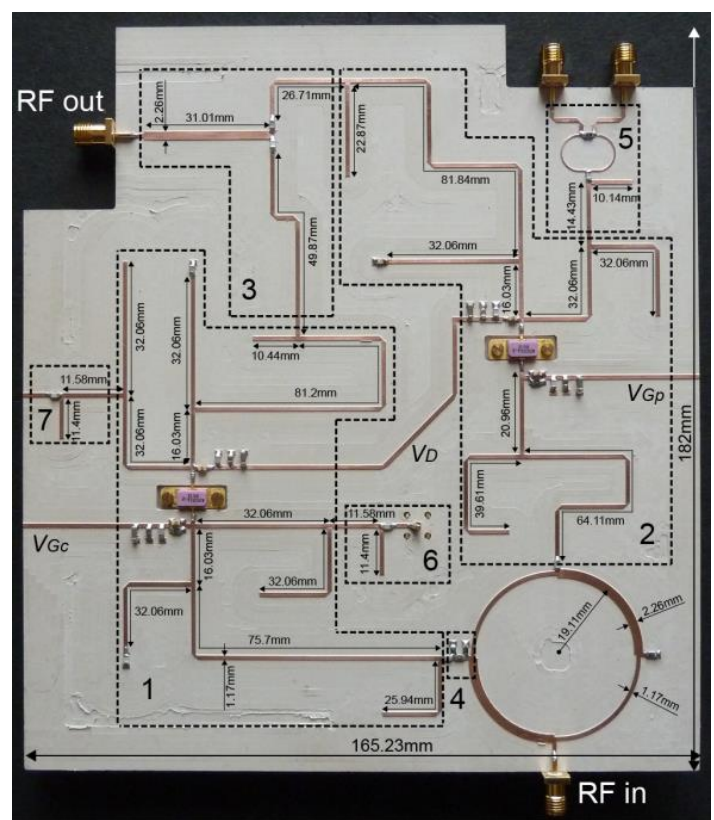

Figure 2. Asymmetrical two-way Doherty amplifier

methods 1 and 2, but in the alternate channels they are augmented by $3 \mathrm{~dB}$ (the $1^{\text {st }}$ method) and $6 \mathrm{~dB}$ (the $2^{\text {nd }}$ method).

When DA is tested for 64QAM signal the achieved results of linearization are similar as in the previous case. For $1 \mathrm{dBm}$ input signal power, ACPRs in the adjacent channels increase by $4 \mathrm{~dB}$ for both linearization methods, whereas for $3 \mathrm{dBm}$ input power they become better by $6 \mathrm{~dB}$ for the $1^{\text {st }}$ method and $8 \mathrm{~dB}$ for the $2^{\text {nd }}$ method. With the power increase to $5 \mathrm{dBm}$, ACPRs rise by $3 \mathrm{~dB}$ and $5 \mathrm{~dB}$ in the methods 1 and 2 , respectively. No evident improvement in the alternate channels can be noticed for $1 \mathrm{dBm}$ and $3 \mathrm{dBm}$ input power levels, but it is $4 \mathrm{~dB}$ in case of $5 \mathrm{dBm}$ power.

Comparing the measured results with the simulated results represented in [6], we can infer that the $2^{\text {nd }}$ linearization method achieves slightly better ACPRs improvement in the adjacent channels, especially for higher power, as it was also deduced in [6] when simulated results were analyzed. Even though the simulated results attained for two-tone test show more apparent improvement when the $2^{\text {nd }}$ method is used, it should indicate that for the OFDM signal test in simulation, the less divergence between results accomplished with two linearization methods can be observed for higher power, closer to amplifier saturation region. 


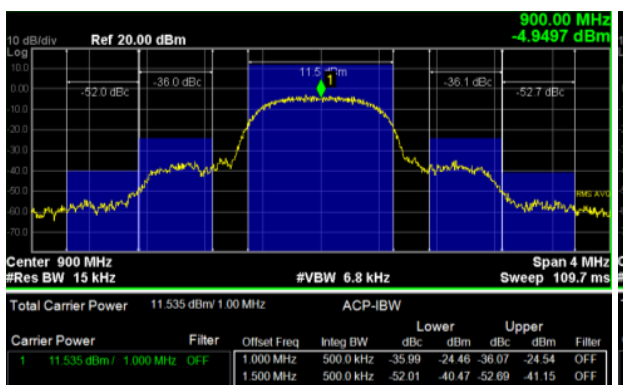

a)

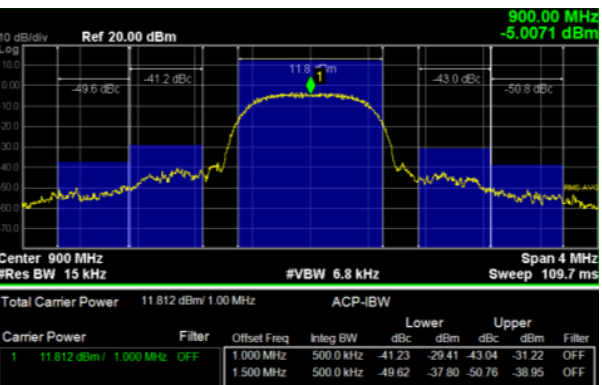

b)

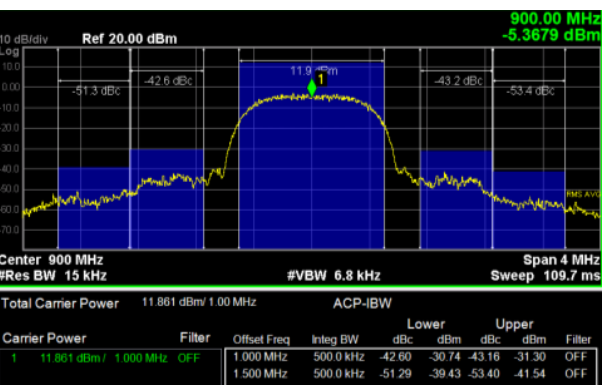

c)

Figure 3. Output spectrum for 16QAM signal of $1 \mathrm{MHz}$ useful signal frequency bandwidth for input signal power $1 \mathrm{dBm}$ a) before linearization; b) after linearization by method 1; c) after linearization by method 2

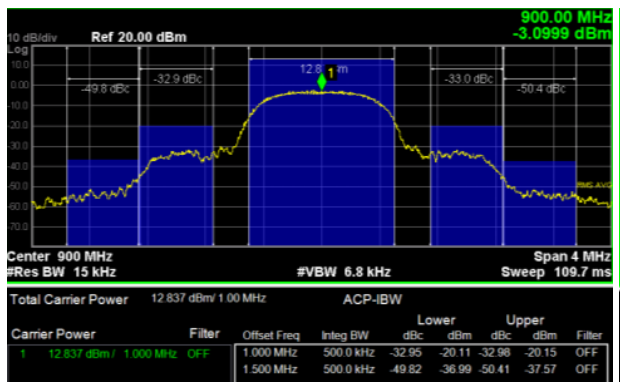

a)

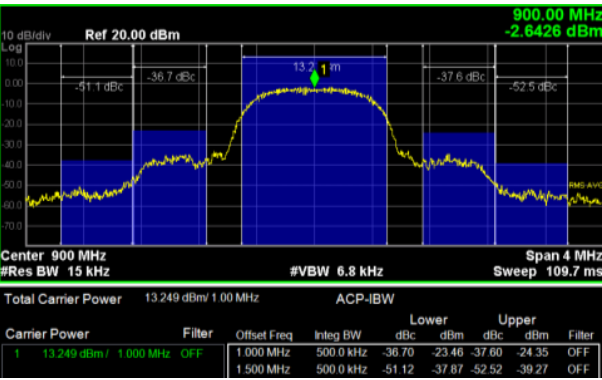

b)

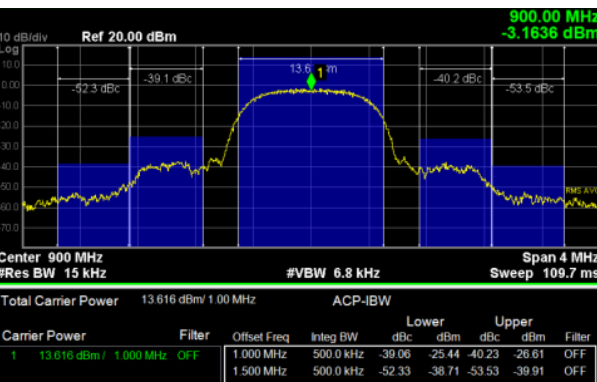

c)

Figure 4. Output spectrum for 16QAM signal of $1 \mathrm{MHz}$ useful signal frequency bandwidth for input signal power $3 \mathrm{dBm}$ a) before linearization; b) after linearization by method 1; c) after linearization by method 2

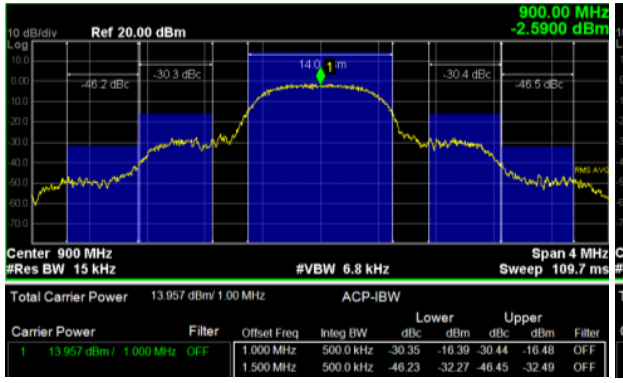

a)

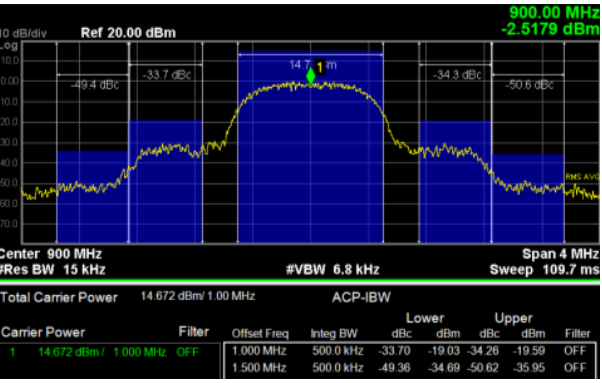

b)

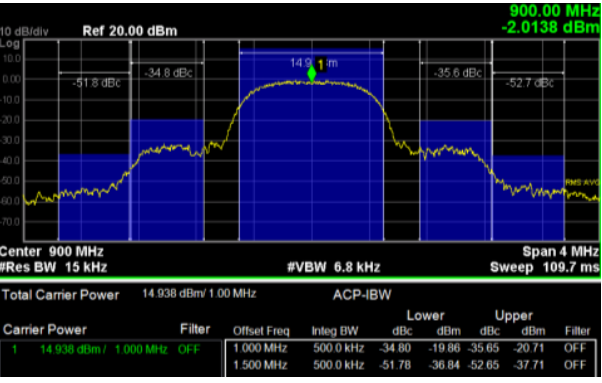

c)

Figure 5. Output spectrum for 16QAM signal of $1 \mathrm{MHz}$ useful signal frequency bandwidth for input signal power $5 \mathrm{dBm}$ a) before linearization; b) after linearization by method 1 ; c) after linearization by method 2

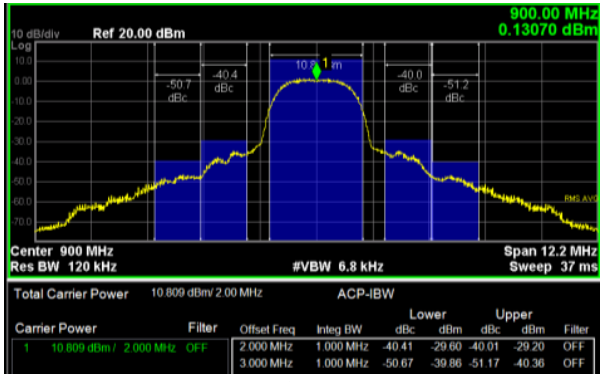

a)

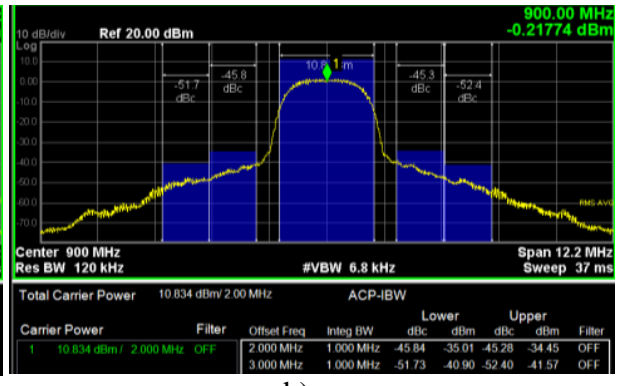

b)

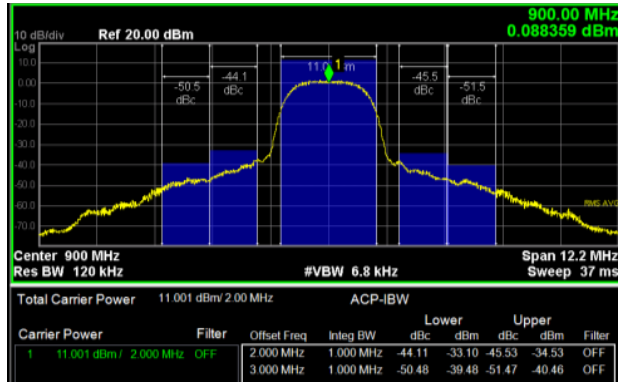

c)

Figure 6. Output spectrum for 64QAM signal of $2 \mathrm{MHz}$ useful signal frequency bandwidth for input signal power $1 \mathrm{dBm}$ a) before linearization; b) after linearization by method 1 ; c) after linearization by method 2 


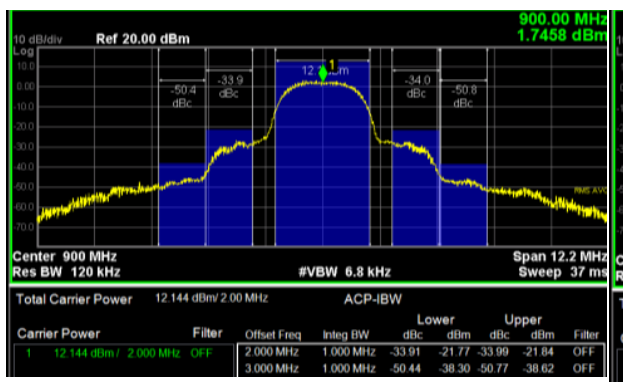

a)

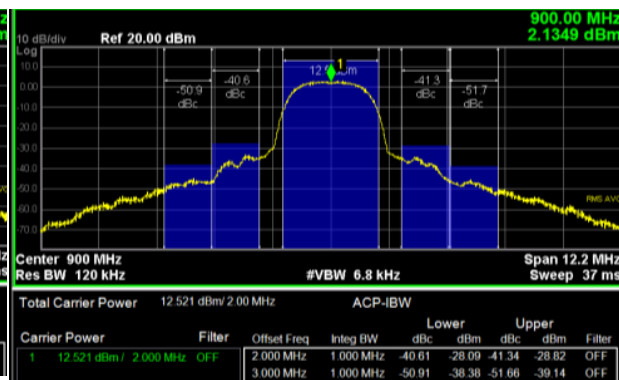

b)

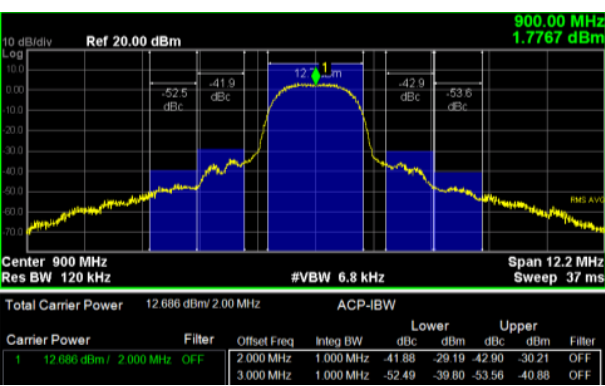

c)

Figure 7. Output spectrum for 64QAM signal of $2 \mathrm{MHz}$ useful signal frequency bandwidth for input signal power $3 \mathrm{dBm}$ a) before linearization; b) after linearization by method 1 ; c) after linearization by method 2

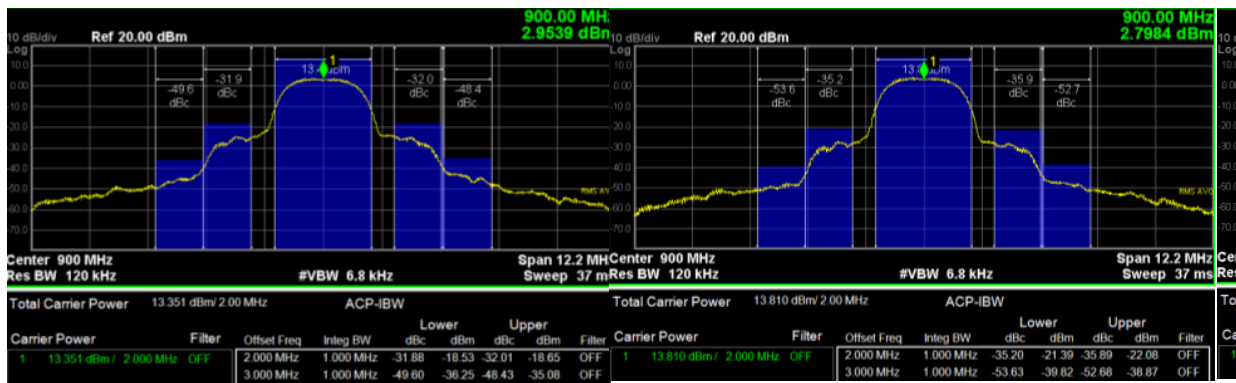

a) b)

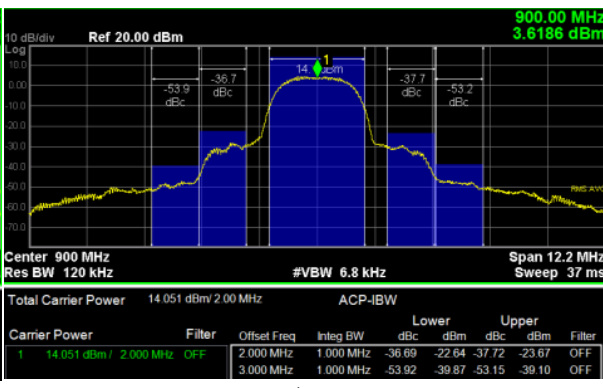

c)

Figure 8. Output spectrum for 64QAM signal of $2 \mathrm{MHz}$ useful signal frequency bandwidth for input signal power $5 \mathrm{dBm}$ a) before linearization; b) after linearization by method 1; c) after linearization by method 2

\section{CONCLUSION}

Experimental results of the linearization of asymmetrical Doherty amplifier fabricated in microstrip technology obtained by applying two digital linearization methods are presented in this paper. The linearization methods utilize the adequately processed baseband digital signals that modulate the second harmonic of the fundamental carrier. In the $1^{\text {st }}$ linearization method, formed signals for the linearization are injected at the input and output of main transistor in Doherty amplifier, while in the $2^{\text {nd }}$ method these signals are led to the outputs of the main and auxiliary amplifier transistors in the DA circuit. The NI USRP platforms programmed by LabView software were used for generation of the useful 16QAM and 64QAM signals for DA test and measurements of ACPRs in adjacent and alternate channels for various input power levels. Additionally, these platforms form the signals for linearization, and process them in amplitude and phase. Measurements performed by signal analyzer illustrate the results of the linearization for two applied linearization methods and compare them to the states before the linearization.

On the bases of the achieved results, it can be noticed that the $2^{\text {nd }}$ method provides slightly better results for higher power then the application of the $1^{\text {st }}$ method regarding adjacent channels, where the $3^{\text {rd }}$-order IM products are dominant. The same conclusion can be derived for the alternate channels (the band of dominant $5^{\text {th }}$-order IM products) but these results of only $1 \mathrm{~dB}$ or $2 \mathrm{~dB}$ are inconsiderable, with the exception of the $5 \mathrm{dBm}$ input power where higher improvements of ACPRs were attained in case of both linearization methods.

\section{ACKNOWLEDGMENT}

Fund for Science of Republic of Serbia supported this work, Grant: 6398983-Programme of collaboration of Serbian science with diaspora-project Digital Even-Order Linearization of 5G Power Amplifiers in Bands below 6GHzDELFIN.

\section{REFERENCES}

[1] S. Jung, O. Hammi, and F. M. Ghannouchi, "Design Optimization and DPD Linearization of GaN-Based Unsymmetrical Doherty Power Amplifiers for 3G Multicarrier Applications", IEEE Transactions on Microwave Theory and Techniques, vol. 57, no. 9, pp. 2105-2013, September 2009.

[2] A. Atanasković, N. Males-Ilić, K. Blau, A. Đorić and B. Milovanović, "RF PA Linearization using Modified Baseband Signal that Modulates Carrier Second Harmonic", Microwave Review, vol. 19, no.2, pp. 119124, December 2013.

[3] A. Đorić, N. Maleš-Ilić, A. Atanasković and V. Marković, "Linearization of Broadband Doherty Amplifier by Baseband Signal that Modulates Second Harmonic", Proc. IEEE EUROCON 2017, Ohrid, Macedonia, 6-8 July, 2017, pp. 206-21.

[4] N. Maleš-Ilić, A. Atanasković, K. Blau, M. Hein, "Linearization of Asymmetrical Doherty Amplifier by the Even-Order Nonlinear Signals", International Journal of Electronics, Taylor \& Francis, Vol.103, Issue No.8, pp.1318-1331, August 2016.

[5] A. Đorić, A. Atanasković, N. Maleš-Ilić, M. Živanović: "Linearization of RF PA by Even-order Nonlinear Baseband Signal Processed in Digital Domain", International Journal of Electronics, Taylor \& Francis, Vol.106, Issue No.12, pp.1904-1918, December 2019.

[6] A. Đorić, A. Atanasković, B. Alorda, N. Maleš-Ilić: "Linearization of Doherty Amplifier by Injection of Digitally Processed Baseband Signals at the Output of the Main and Auxiliary Cell", Proceedings of the 14th International Conference on Advanced Technologies, Systems and Services in Telecommunications - TELSIKS 2019, Niš, Serbia, October 23-25. 